Faculty of Engineering

Faculty Publications

This is a post-print version of the following article:

Not Just an Academic Exercise: Systems Thinking Applied to Designing Safer Alternatives

Megan R. Schwarzman \& Heather L. Buckley

2019

The final publication is available at:

https://doi.org/10.1021/acs.jchemed.9b00345

Citation for this paper:

Schwarzman, M. R. \& Buckley, H. L. (2019). Not just an academic exercise: Systems thinking applied to designing safer alternatives. Journal of Chemical Education, 96(12), 2984-2992. https://doi.org/10.1021/acs.jchemed.9b00345 


\section{Not Just an Academic Exercise: Systems thinking applied to designing safer alternatives}

Megan R. Schwarzman, ${ }^{*}$ Heather L. Buckley²

${ }^{1}$ School of Public Health, University of California, Berkeley, 2121 Berkeley Way \#5302, Berkeley, CA 94720-7360, United States

${ }^{2}$ Department of Civil engineering and Department of Chemistry, University of Victoria, 3800 Finnerty Rd, Victoria, BC, Canada V8P 5C2

\section{ABSTRACT}

For the last seven years, an interdisciplinary course known as Greener Solutions, offered by the

University of California, Berkeley Center for Green Chemistry has brought together graduate students in chemistry, environmental health and engineering to understand each other's disciplines and, on that basis, work together to develop safer alternatives to hazardous chemicals and manufacturing processes. Through the course, interdisciplinary teams of UC Berkeley students have worked with partner organizations to identify safer alternatives to chemicals of concern, including investigating safer preservatives in personal care products, non-fluorinated durable water-repellant coatings for outerwear, and safer crosslinkers to replace formaldehyde in permanent press textiles and diisocyanates in spray polyurethane foam insulation. Students engage in a bio-inspired design process and then assess the potential health and environmental hazards associated with each of their proposed alternatives relative to those posed by the chemicals currently used in the application. The students generate a focused alternatives assessment that considers technical performance, relative hazard and exposure potential, and feasibility, creating an "opportunity map" for the partner company and, ideally, the industry sector as a whole. The Greener Solutions model for interdisciplinary, inquirybased learning is training a new generation of chemists and engineers in a systems approach to design: one that more fully considers the health and environmental implications of chemical and material choices. An adaptation of the Greener Solutions course model to serve undergraduate civil engineering students at University of Victoria, B.C. demonstrates how the course elements can serve a different subject matter and instructional level. 


\section{GRAPHICAL ABSTRACT}

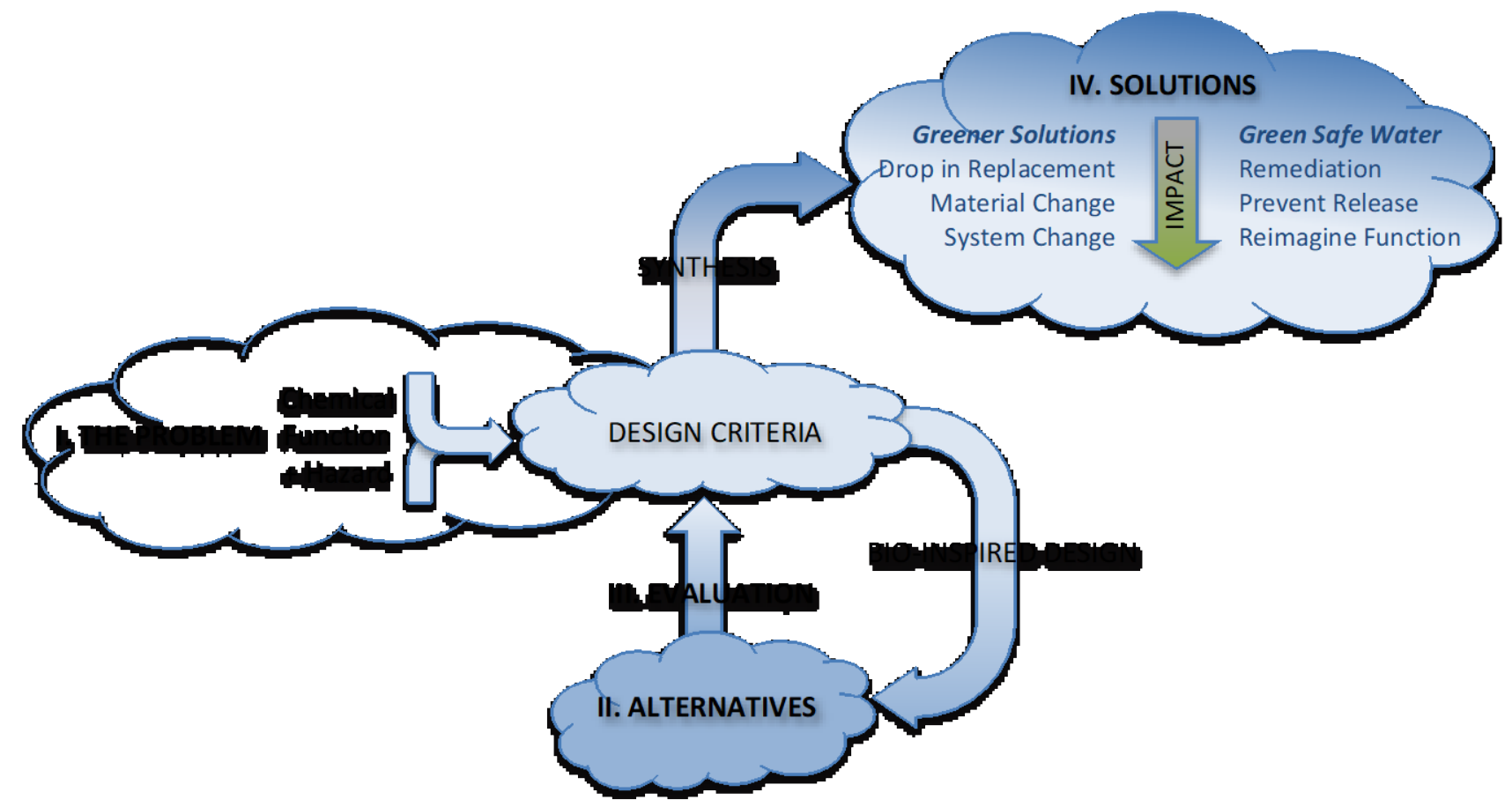

\section{KEYWORDS}

General Public, Curriculum, Inquiry-Based/Discovery Learning, Problem Solving/Decision Making, Applications of Chemistry, Consumer Chemistry, Green Chemistry, Industrial Chemistry, Learning Theories, Materials Science.

\section{INTRODUCTION}

The need for safer alternatives to hazardous chemicals

In 2018, the Lancet Commission on Pollution and Health identified environmental pollution, including workplace exposures, as the leading cause of death worldwide, as well as a significant economic drain, costing an estimated $\$ 53$ billion annually in lost productivity alone. ${ }^{1}$ The production, use and disposal of chemicals and products contributes significantly to this burden-the chemical industry relies overwhelmingly on fossil fuel feedstocks and produces chemicals and materials that are key sources of human and ecosystem exposure to toxic substances. For example, pesticides, coatings, printing inks, adhesives, cleaning agents, and personal care products now make up half of all VOC emissions from fossil fuels in industrialized cities. ${ }^{2}$ New regulatory programs, such as California's Safer Consumer Products Program, ${ }^{3}$ have emerged, with the goals of shifting entire sectors toward safer alternatives, and away from well-recognized chemicals of concern. Consumers are likewise increasingly demanding safer alternatives, and the chemical enterprise, including product formulators, 
manufacturers, brands, and retailers are responding. Some of the nation's largest retailers, such as Wal-Mart ${ }^{4}$ and Target ${ }^{5}$ have launched initiatives to eliminate hazardous chemicals from the personal care and cleaning products they sell. By 2020, the global market for green chemistry is projected to reach $\$ 100$ billion. $^{6}$

When rigorously applied, green chemistry can guide the redesign of chemical processes and products to reduce toxicity and energy consumption, and to increase the use of renewable sources of both energy and materials.7,8 Research at the intersection of public health, green chemistry and green engineering 9 has dispelled the notion that pollution is an inevitable consequence of economic development; instead, the chemical enterprise itself could serve as a primary source of the innovation that advances the science and commercial applications of safer, more sustainable chemistry.

Changing how we train the next generation of chemists

For the chemical enterprise to lead this transition to safer, more sustainable processes and products, we must train the next generation of practitioners to navigate the interconnections between chemistry and the global environment. ${ }^{10,11}$ Chemists can play a significant role in improving the safety of chemicals on the market by influencing chemical design and selection to reduce resource consumption, eliminate toxics, and reduce environmental impact throughout chemical manufacturing, use, and disposal. ${ }^{12}$ Universities can equip chemists with the technical tools to exert this influence, both through the principles of inherent safety in chemical and process design, and through practical strategies. These are precisely the goals of the Greener Solutions program developed by the University of California, Berkeley Center for Green Chemistry.

\section{COURSE STRUCTURE}

The Greener Solutions model

Greener Solutions is a 3-unit inquiry-based course in which teams of graduate students from chemistry, engineering and public health research safer alternatives to hazardous chemicals used in a product or manufacturing process, responding to a specific challenge posed by a partner company. Organizing students into interdisciplinary teams introduces chemists to the health and environmental implications of the chemistries they develop at the same time as it introduces non-chemists to the central role of chemistry in creating the material economy. Grounding the Greener Solutions course in 
the chemistry of tangible products, and in a real-life challenge posed by a partner company, provides a common platform for the chemists and non-chemists to creatively apply their expertise.

As they search for safer alternatives, students gain practical experience in green chemistry and bioinspired design, along with toxicology and environmental health, communication of complex scientific ideas, and strategies to overcome institutional and policy barriers to the adoption of safer chemistries. The semester-long project culminates in a final report, poster, and presentation to the partner organization and to the public.

An interdisciplinary teaching team of three instructors (supplemented by guest lecturers) provides expertise in the fields of chemistry, environmental health, toxicology, bio-inspired design (BID), and chemicals policy. Lectures, discussion and assignments support the technical aspects of the project, while additional sessions teach process-oriented skills, such as interdisciplinary research methods, strategies for high-performing teams, and effective written and oral communication. Over the course of the semester, students are guided through four distinct steps: problem definition, identifying alternatives, hazard assessment, and final synthesis and recommendations; we discuss each in detail below.

An adaptation: The Green Safe Water course

A graduate of Greener Solutions has adapted the course model to serve undergraduate civil engineering students at University of Victoria, B.C. This new course, Green Safe Water, demonstrates how the Greener Solutions approach can serve a different subject matter and instructional level. While Greener Solutions students seek alternatives to a hazardous chemical in a product or manufacturing process, students in Green Safe Water research interventions to address the presence of a hazardous metal in drinking water.

These student teams first study how anthropogenically-derived metals interact with natural systems and find their way into drinking water and other environmental compartments. For a class of fourth year Civil Engineering undergraduates, this means building on first-year chemistry concepts and applying them in the context of water treatment technologies. From there, students investigate an anthropogenic source of their chosen metal and articulate the function of the metal in that context. The teams are trained in chemical hazard assessment, and they apply life cycle analysis skills from their engineering program to define system boundaries and map a material flow of the metal from 
source to tap. They then design interventions at three points along this material flow, seeking ways to prevent their metal from contaminating drinking water. Finally, they evaluate each of these proposed interventions qualitatively according to their relative hazards, feasibility and scale of impact.

Like in Greener Solutions, students in Green Safe Water design solutions using a BID process and recommend systems-level interventions that span scales and often effectively address challenges beyond the more limited scope of a drop-in chemical substitute that can emerge from a chemical alternatives assessment, as defined by the U.S. EPA. ${ }^{13}$

Below, we outline in detail the steps of Greener Solutions (Figure 1) and then discuss how the Green Safe Water course adapts this model.

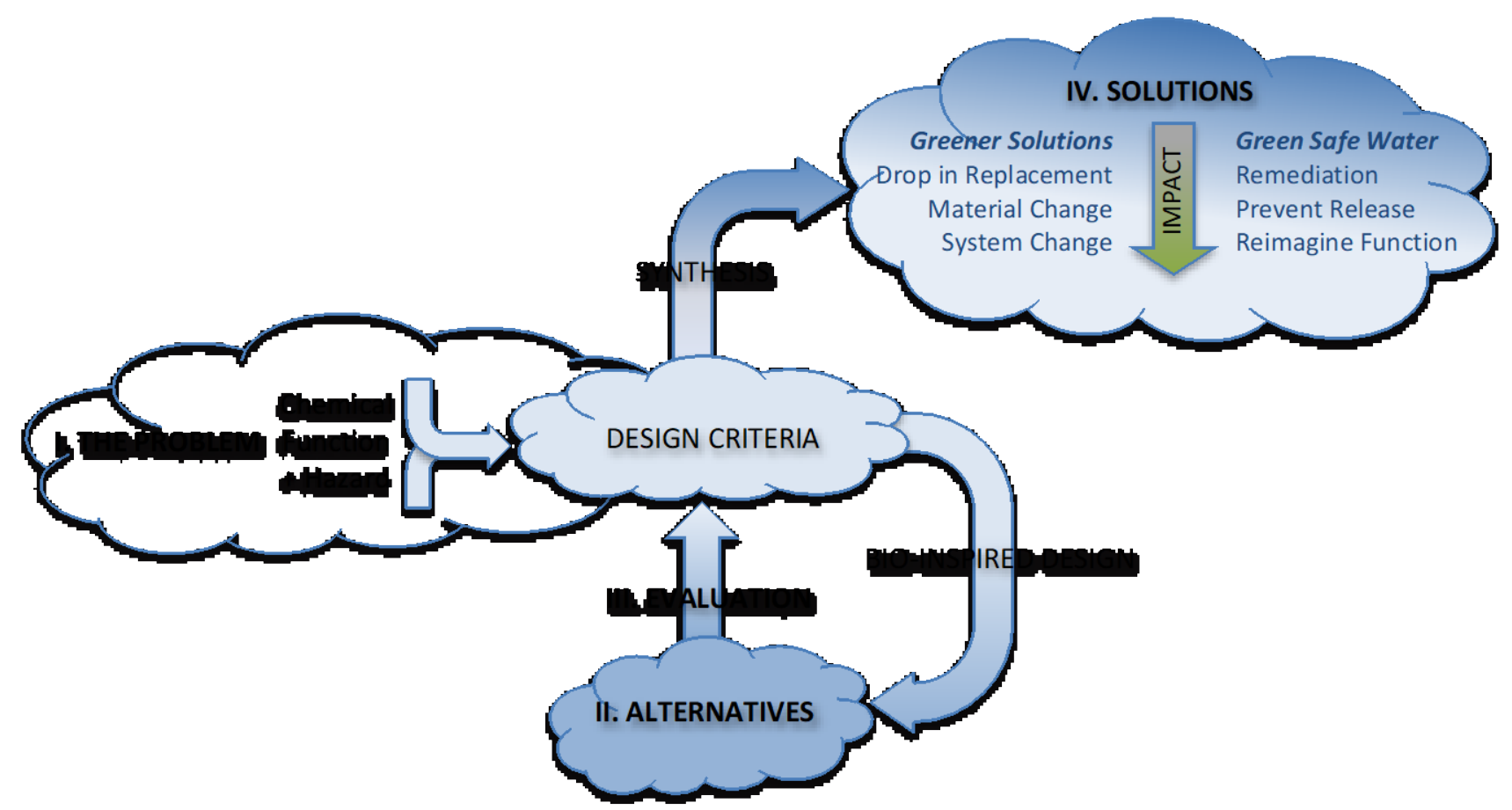

Figure 1. The overall structure and flow of the research process employed by students in both the Greener Solutions and Green Safe Water courses. Central to the model is the iterative nature of the problem-framing and problem-solving process; understanding the problem generates design criteria, and the alternatives are evaluated according to those design criteria, with adjustment along the way as the research matures.

Greener Solutions Step I: Define the problem

During the summer prior to the course, partner organizations work with course faculty to design a challenge, starting with a specific chemical of concern in their products and identifying a pre-

competitive question related to achieving the same chemical function more safely (see Table 1 for past project challenges). The challenge scope must be suitable for a semester-long inquiry, and address a problem encountered across an industry sector, rather than a question tied to a single company's 
value proposition. Projects thus avoid non-disclosure agreements, leaving students free to discuss and publish their work, and encouraging partner companies to share the outcome with others in their sector and increase their transparency with customers.

Table 1. Greener Solutions project challenges and partner organizations, 2012-2018

\begin{tabular}{|c|c|c|}
\hline Year & Challenge & Partner Organization(s) \\
\hline 2012 & Identifying emerging contaminants from e-waste & Hewlett Packard \\
\hline 2013 & Alternatives to formaldehyde in permanent press garments & Levi Strauss \& Co. \\
\hline \multirow{3}{*}{2014} & & Seventh Generation, Method, \\
\hline & Safer preservatives for personal care products & \\
\hline & & Beautycounter \\
\hline 2014 & Alternatives to spray polyurethane foam insulation & General Coatings, California EPA \\
\hline 2015 & Inherently safer 3D printing resins & Autodesk \\
\hline 2015 & Safer surfactants for low-temperature cleaning products & Method, Amrys \\
\hline 2016 & Alternative colorant methods for polymer furniture & Steelcase \\
\hline 2016 & Inherently safe mosquito-repellant clothing & Patagonia \\
\hline 2016 & Biodegradable pigments for marine coatings & Mango Materials \\
\hline 2017 & Durable water-repellent coating for outerwear & W.L. Gore \\
\hline 2017 & Bio-based treatments for mycelium "leather" & MycoWorks \\
\hline 2018 & Safer UV blockers for sunscreens & Method \\
\hline 2018 & Redesigning polymer packaging to prevent ocean contamination & Method \\
\hline 2018 & Safer UV blockers for roofing materials & Oakland Ecoblock \\
\hline
\end{tabular}

We form interdisciplinary teams of three to five graduate students, typically including at least one student in synthetic chemistry, one in environmental health science (including molecular toxicology and industrial hygiene) and one in engineering (including environmental engineering, material science and mechanical engineering).

Once introduced to their challenge, the student teams outline key questions and their proposed approach to researching the challenge, and communicate these to their partner company through a Scope of Work.

Their inquiry then begins by identifying the core function served by the chemical of concern, such as crosslinking (e.g., to replace formaldehyde or diisocyanates), or antimicrobial activity (to replace parabens or methylisothiazolinone). They then research the technical constraints of the system they 
will be working in (e.g., personal care product formulation, or textile manufacturing). They perform literature reviews and consult academic experts as well as the formulating chemists or material scientists at their partner organization. Students learn about the production process, the materials used, how their constituent chemicals interact, and the relevant lifecycle processes.

Simultaneous with researching technical performance criteria for the existing hazardous chemical and its eventual replacement, students develop the environmental health performance criteria they will use to assess the alternatives. Chemists and engineers are accustomed to working under design constraints, however these rarely include criteria for reducing toxicity. By defining biological, ecological and health impacts as performance criteria in the earliest phases of chemical design, the course reframes design: instead of presenting health and environmental impacts as obstacles (e.g., "many polyfluorinated compounds provide excellent oleophobicity, but their persistence and toxicity make them unacceptable") the environmental health performance criteria can instead provide intriguing design constraints (e.g., "what kind of surface sheds water using non-toxic materials and structures?").

At this stage, student teams summarize their understanding of the technical context in a presentation to the class, including the key criteria they will use to evaluate both the technical and environmental health performance of their proposed solutions.

\section{Greener Solutions Step II: Identify alternatives-from biology to chemistry}

With performance criteria in hand, student teams begin their search for safer alternatives. Using the chemical function identified in the first step of their research, students turn to biology, asking the question, "How does biology accomplish this function?" This initiates the process of bio-inspired design (BID), defined as, "the study and translation to technology of biological forms, processes, and systems in order to solve human challenges;"14 biology offers a few billion years of innovation to plumb for design inspiration. Applied to a formal design process, BID is often a path to identifying safer, more resilient materials that also conserve resources and energy.

Following 12 guiding BID concepts, ${ }^{14}$ students search the biological literature for organisms that use materials, processes or systems to accomplish the core chemical function in their challenge. When students identify a promising biological strategy, they then characterize the constituent chemistry in detail and identify non-biological materials and methods that could perform that function. In this way, 
students work from the principles they identify in biological systems to design a solution that is bioinspired, rather than one that uses the biological material directly, a contrasting process known as bio-utilization. ${ }^{16}$ BID challenges students to think about a range of potential alternatives, looking to biology not only for possible drop-in chemical alternatives, but also for material or structural solutions that obviate the need for a chemical replacement.

For example, a Greener Solutions team undertook a BID approach to designing a safer resin for stereolithography (SLA) printing, a type of additive manufacturing that creates solid objects layer-bylayer using UV light to polymerize a liquid resin. The student team investigated how mussels and oysters use $\mathrm{pH}$ changes to produce their anchoring adhesives in the intertidal environment. Students wondered if a pH change, rather than UV light, could work to activate the SLA material phase-change from liquid to solid. They ultimately identified a new chemical formula that could change the $\mathrm{pH}$ in a resin material, causing it to solidify. In this way, the students adapted the chemical mechanism employed by mollusks to an entirely different setting: the interrelated components of the SLA process.

In this second stage, students generate a list of possible alternative strategies and a corresponding list of the constituent chemicals used in each strategy.

Greener Solutions Step III: Compare chemical hazards within a systems thinking framework assessment, comparing the potential health and environmental impacts of chemicals in the existing product to the impacts of chemicals used in each proposed alternative strategy. Students identify hazards that could arise from each stage of the product lifecycle, including raw material extraction, transportation, chemical synthesis, material manufacturing, product use, and end-of-life management. They are likewise required to evaluate all potential sources of exposure to chemical hazards, including in occupational settings or to the general population via product use or contaminated air, soil, water, or foods.

The goal of the comparative hazard assessment is to identify alternatives that are inherently safer over alternatives that might only reduce exposure to a hazardous chemical during one phase of the product lifecycle while shifting risk to another part of the product lifecycle. While some proposed solutions center around new chemistry (e.g. a preservatives challenge that identified several promising classes of natural compounds with antimicrobial activity, including terpenes and flavonoids), others 
point companies away from drop-in chemical substitutions and toward entirely new design approaches. For example, students investigating safer alternatives to the diisocyanates used as crosslinkers in spray polyurethane foam insulation steered their partner company away from simply polymerizing the isocyanate, which makes the hazardous chemical less bioavailable during application but does little to protect workers upstream in the manufacturing process. Among their longer-term solutions was a proposal to redesign the crosslinking reaction to use a single non-toxic ingredient that could self-crosslink in the presence of a salt catalyst and a $\mathrm{pH}$ change. ${ }^{17}$

Exposure potential can appropriately be used where it helps differentiate among chemicals that otherwise lack hazard data. For example, teams might avoid organic chemicals that bioaccumulate or persist in the environment, understanding that the impact of any hazards posed by those substances would increase over time and pose real challenges for remediation.

We teach a systematic approach to searching for hazard data that begins with authoritative classifications found in the Chemical Hazard Data Commons, ${ }^{18}$ followed by a search of academic literature for additional data. Students organize their findings according to the criteria in the publicly available GreenScreen for Safer Chemicals hazard assessment method. ${ }^{19}$ Where authoritative assessments or experimental data are unavailable, students employ predictive toxicology tools to estimate chemical characteristics relevant to hazard or exposure.

The product of this step is a comparative hazard table and an accompanying description that characterizes the overall hazards of proposed alternative strategies relative to the current technology and summarizes the extent and potential impact of data gaps.

Greener Solutions Step IV: Put it all together in an "Opportunity Map"

Students synthesize the information they have gathered into a focused alternatives assessment, summarizing the technical feasibility and the relative hazards and exposure potential of the constituent chemicals in each of their proposed strategies. Because the likelihood that an industry will adopt a potentially safer substitute also hinges on the alternative's economic feasibility and market acceptance, ${ }^{20}$ students gather any readily available information on cost and marketability of a solution, although these factors mainly fall outside the scope of the course. These summary analyses 225 are presented to the partner organizations with recommendations specific to the priorities of each partner organization. The semester ends with this "opportunity map" (in the form of a final report, 
poster and presentation) recommending a range of possible solutions. Example figures used in student teams' opportunity maps are shown in Figure 2 and Figure 3. Examples of students' final reports and posters are provided in SI.

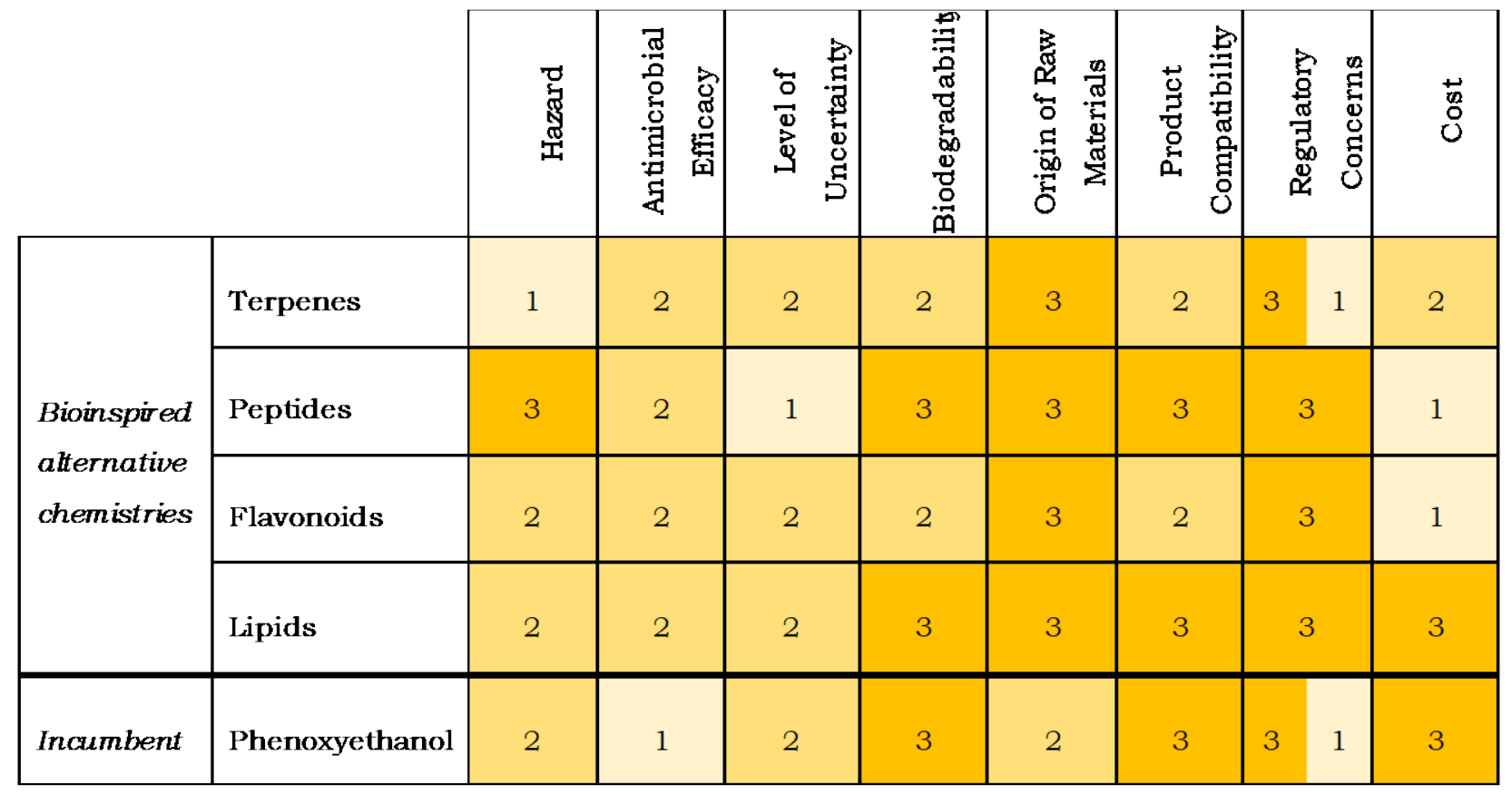

Figure 2: Example of student-generated opportunity map summary figure, a multi-criteria decision-making framework comparing an existing preservative in personal care product formulations and their proposed bioinspired alternatives. Higher scores/darker colors are better (i.e. a score of 3 indicates low hazard, high biodegradability). ${ }^{21}$ 


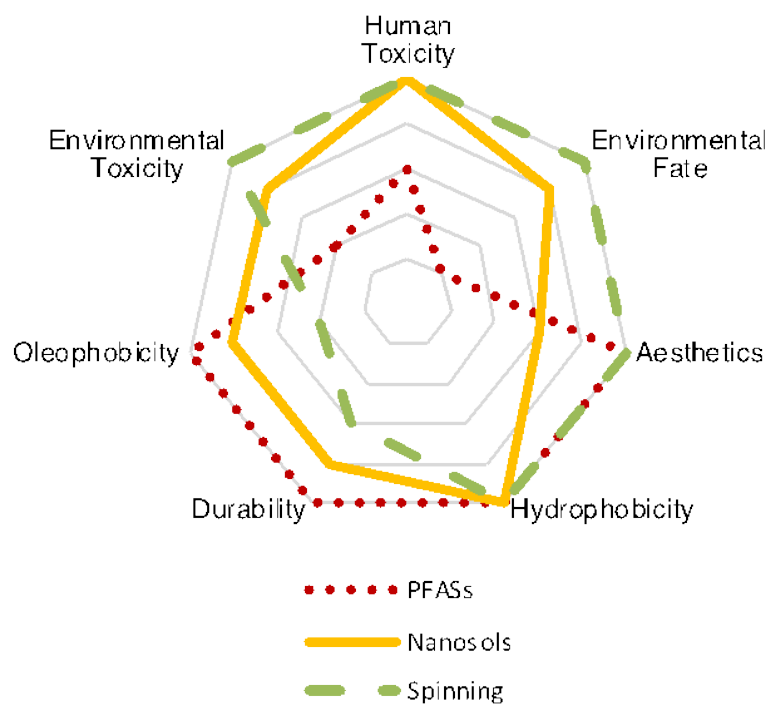

Figure 3: Example of student-generated opportunity map summary figure, a multi-criteria decision-making framework comparing fluorinated compounds used in durable water repellant coatings for outerwear to proposed bioinspired alternatives. Values farther from the center are better (i.e., lower toxicity, higher hydrophobicity). PFAS is per- and polyfluoroalkyl substances. ${ }^{22}$

Tuning these steps for an undergraduate Civil Engineering Course: Green Safe Water

While the general structure of the two courses is parallel, working with undergraduate students from a single discipline requires Green Safe Water to be more prescriptive in some elements than is Greener Solutions. Students are asked to design a solution that prevents human consumption of a particular trace metal contaminant via drinking water, with a secondary goal of protecting ecosystems (see Table 2 for example projects). Students spend more time in the problem space, first applying chemistry knowledge developed in the course to predict all possible metal compounds that may form in the environment from the parent contaminant, and then learning how to identify the hazards associated with those metal species. Student teams then create a materials flow map for their metal, outlining its industrial function, how it enters the environment, and pathways to the tap. To provide undergraduates with a more constrained scope, Green Safe Water asks students to generate recommendations specific to each of three possible intervention points that they identify on their materials flow map. The students' engineering training provides the skills to first identify places to intervene from a solutions-agnostic perspective, and subsequently to design (using BID principles) alternative strategies at those points and evaluate their proposed solutions. Like in Greener Solutions, specific sessions teach core technical skills, but for undergraduates Green Safe Water adds material to help students critically evaluate information sources (e.g. a company website is likely reliable for 
explaining the process of steel passivation with chromium, but a government agency report is less prone to bias when reporting chromium levels in watersheds).

Table 2. Green Safe Water challenges and partners, 2018-2019

\begin{tabular}{lll}
\hline Year & Challenge & Partner Organization \\
\hline 2018 & Chromium in steel passivation & \\
2018 & Copper in antifouling boat paint & \\
2018 & Arsenic in wood preservation & Artisanal Gold Council \\
2018 & Mercury in artisanal gold mining (ASGM) & \\
2019 & Lead in car batteries & \\
2019 & Chromium in leather tanning & \\
2019 & Tin in plastic stabilizers & Tiedje Group \\
2019 & Cadmium telluride in solar panels & \\
\hline
\end{tabular}

In both Greener Solutions and in Green Safe Water, we recognize that success is contingent on having high functioning teams with good communication channels, and that this needs to be established early in the semester. Both classes use a full class period in the first weeks to engage in a team-building activity, followed by a discussion of team roles in the activity, the importance of defined team roles and practices throughout a project, and an opportunity to share individual goals and craft a team mission. We then review these goals mid-semester, along with the peer evaluation feedback form used at the end of term (see SI), to help teams identify opportunities to improve their communication and progress towards their stated goals.

\section{Student assessment}

Greener Solutions students are graded on the six assignments that serve as deliverables for each step of the research (e.g., Scope of Work, Strategy and Chemical List, Hazard Assessment, etc.) in addition to the final deliverables (presentation, poster and report), and group participation. We allocating most of the points to the final deliverables to reduce grading pressure on the earlier assignments, since those flow from the most creative and exploratory parts of the research. For each deliverable, we provide multiple examples from past years, and for in-class presentations instructor 
feedback is complemented by structured feedback from the other student groups (see SI for student comment form). Because students submit all assignments as a team, the peer evaluation at the end of the semester helps to identify any imbalances in students' contributions.

In Green Safe Water, students start the semester with four content-oriented classes to solidify their chemistry knowledge around metals in water; this material is evaluated by a combination of prereading quizzes to support a flipped classroom teaching model, and a more traditional unit test of multiple choice and short-answer questions. The remainder of the course is divided into six major deliverables: a scope of work, a metals speciation map, a hazard assessment, a life cycle map of the industrial function of the assigned metal and application, a presentation of proposed interventions, and a final report and presentation. The first two are submitted as drafts for ungraded formative feedback before the graded version. Each of these major deliverables is submitted as a group, but all have process deliverables that are individually evaluated (reading reflections, research logs, and a library database assignment) to calibrate student engagement and understanding. Like with Greener Solutions, the in-term deliverables all contribute heavily to the final product, and are weighted less heavily, with the final report and presentation, along with peer evaluations and class participation comprising a large portion of the grade.

\section{GREENER SOLUTIONS OUTCOMES}

Greener Solutions is typically highly reviewed by students (most recently the course received an overall effectiveness score of 6.3 out of 7 , compared to the Department average score of 5.9/7). Students have called Greener Solutions, "the most useful/ highest impact course I took at Berkeley." They often highlight the importance of the interdisciplinary and applied nature of the course with comments such as, "I learned way more (and had a lot more fun learning it) than in a typical lecturebased course. It was really valuable to have instructors from different fields and perspectives." And "I loved the research aspect of this course and was super excited to delve into an issue of interest.”

\section{Career trajectories}

Perhaps the most telling outcome of Greener Solutions is the accomplishments of our graduates, many of whose career paths change after taking the course, ultimately drawing directly from the 
knowledge and systems-thinking skills they gained in the course. Chemistry doctoral students who took the course have applied their knowledge of green chemistry at leading companies and well as non-profits and government agencies (see SI for list). As one former chemistry student wrote of the impact of Greener Solutions on his career:

Vocationally, I grew more in [this course] than I had in the previous four years of my formal PhD program. I used the skills and philosophy obtained [in the course] to start a cooperative research and development program...dedicated to developing safer chemistry and materials for industry and agriculture. The training and philosophy [from Greener Solutions] provided me with a uniquely valuable skill set that I employ daily....The educational function of the course is critical for chemistry students, as the chemistry graduate program currently does not address chemical toxicology or environmental safety.

This supports the notion that educating chemists and engineers in the environmental health sciences can recruit them to advance public health goals in their own work.

\section{DISCUSSION}

Three elements distinguish Greener Solutions from typical graduate courses in chemistry: it is an applied, problem-based course that relies on interdisciplinary teams to answer a question from a systems-thinking perspective. While problem-based design courses are increasingly common in undergraduate engineering programs, Green Safe Water likewise incorporates interdisciplinary and systems-thinking approaches in applied ways that are new to civil engineering curricula.

\section{Systems thinking in the Greener Solutions model}

Systems thinking provides a means of anticipating and avoiding complications that can arise when conventional thinking is applied to complex problems. The conventional problem solving approach risks, for example, improving the efficiency of a synthetic process without addressing its toxicity, or creating renewable energy technologies (to solve one problem) using hazardous materials (that create a different problem). ${ }^{8,9}$ Instead, systems thinking recognizes that problems arise within a system of interrelated components connected by feedback loops that generate patterns of behavior over time. ${ }^{23}$ Investigating the relationship between the structure of a system and its behavior reveals leverage points where one can fundamentally shift the function or orientation of the entire system. ${ }^{23,24}$

When applied to chemistry, systems thinking requires careful consideration of the ways that chemicals and materials are transformed into products, and how they interact with and affect human health, ecosystems and economic systems over the course of the material's manufacture, use and 
disposal. ${ }^{11}$ This is what our students consider when they evaluate the potential health and environmental impacts over the complete lifecycle of a chemical of concern and its possible alternatives.

By asking students to replace the function of a hazardous chemical within a system, both courses define the inquiry broadly, requiring students to seek multiple points to intervene in a system that previously relied on hazardous chemicals. Framing the inquiry through function enables a solutionoriented, rather than risk-management approach ${ }^{25}$ in which the students compare multiple options for accomplishing a particular function or service (e.g., flame retardancy), rather than attempting to identify the least harmful among a set of structurally similar chemicals (e.g., organohalogen vs. phosphate flame retardants).

The BID process likewise engages students in systems thinking as they investigate complex biological systems and identify how the relationships among their component materials, structures or processes create the desired functions. For example, the hierarchical scale of the silver ragwort leaf structure produces a surface texture at the nano- and micro scale that is nearly superhydrophobic. ${ }^{26}$ One team of Greener Solutions students drew on this structure as inspiration for their strategy to replace perfluorinated durable water-repellent outerwear treatment with an electrospun fiber surface. Likewise, students in Green Safe Water noted that similar structures could prevent biofilm formation and proposed them as an alternative for copper-based antifouling boat paints.

Teaching systems thinking by teaching how to frame and solve problems

While the research process is described above in distinct steps, student teams actually undertake multiple iterations of each of these steps, as shown in Figure 1. A key goal of this process is to teach students how to frame and solve problems, facilitating deep investigation of their challenge, while also equipping them to tackle interesting and meaningful challenges in their future academic and professional work.

Literature on design thinking articulates four distinct capabilities: the ability to observe and notice; frame and reframe; imagine and design; and make and experiment. ${ }^{27}$ Each step of the inquiry process involves significant feedback among the four elements, in that -for example- observations can reveal that an initial problem-framing left something out and can inform the process of reframing the problem. 
Conceiving of problem-framing as a dynamic rather than a one-time activity facilitates systems thinking, and is a critical workplace skill for chemists and engineers-one that is often missed even in otherwise excellent design courses. In addition to building capacity for systematic inquiry, a systems thinking approach aims to avoid the unintended consequences of more reductionist modes of problem solving. The science of toxics is replete with examples of risk-shifting that occur when a wellintentioned solution fails to account for impacts in an area outside the initial problem frame. Embedding the specific project challenges in a more general framework for framing and solving problems generates a highly creative yet structured process of inquiry. It often produces inspiring potential solutions that causing as few unintended consequences as possible, while also teaching a more generally applicable approach to solving complex problems.

Systems thinking is easier to teach in an applied, problem-based context

Both Greener Solutions and Green Safe Water teach technical content in a fully applied, casedbased learning format. Putting the search for safer chemistries and processes into an applied context essentially requires students to employ systems-thinking. As David Constable describes, "[s]ystemsthinking puts chemistry in a real-world context, not just in a flask in the hood of your laboratory. It also asks you to think about how chemistry may be used to provide services and functions to other sciences and end-uses as opposed to being an end all to itself to advance the science of chemistry." 12

In addition to serving the content of the courses, the applied, problem-based structure inspires students; the fact that Greener Solutions research will actually be used by the partner organization seems to elicit uncommonly high-quality work, and students routinely flag this element as a uniquely formative part of their education at Berkeley. One student commented, "I found this course far more interesting and motivating than others I've taken at Berkeley. It was refreshing to feel like my work had impact."

Interdisciplinary teams do some of the teaching for us

In the case of Greener Solutions, because the course asks students to identify the safest way possible of accomplishing a chemical function, chemistry students discover that they need the expertise of students in environmental health sciences, molecular toxicology and environmental engineering to characterize the impact of chemicals on natural systems. Our goal is for them to understand the need for chemical hazard information and to learn what questions to ask, not to know 
the answers. Similarly, even without explicitly interdisciplinary teams, engineering students in Green Safe Water come to recognize the significance of tools outside of their traditional discipline, as well as the value of having core chemistry knowledge and access to experts. Students in both courses learn about the application of their science and its implications for human health and the environment-both elements of systems thinking.

But Greener Solutions' use of interdisciplinary student teams does more than recruit a range of expertise in service of solving a complex problem; it also provides an opportunity for students to learn new subject matter from each other, experience themselves as experts in their own field, and witness each other as experts in fields unfamiliar to them. During the creative phase of the project, the BID process -combined with the functional-use frame-puts students from diverse disciplinary backgrounds on more equal footing, rather than limiting the innovation process to chemists. The disciplines work simultaneously, rather than serially, with complex interactions and feedback along the way. The students learn from each other -rather than from instructors- the importance of understanding the whole system, as well as the type of information they need. As one student described it, "I think it's so valuable to work in cross-disciplinary teams, and I really enjoyed learning from my classmates."

Green Safe Water also employs interdisciplinary learning despite drawing students from a single department, first by being intentional about exposing students to content from several disciplines, and then by explicitly drawing connections among these seemingly disparate types of content. While Green Safe Water is led by a single instructor, her research extends beyond traditional chemistry training to engineering and toxicology, and the course draws on guest expertise to provide material on BID and multidisciplinary database searching. Having demonstrated the success of the course in a single discipline, next year's Green Safe Water will include chemistry students with the aim of benefiting from the peer-to-peer learning demonstrated by Greener Solutions.

420 To ensure that the student groups are in fact high-functioning teams, both courses devote time early in the semester to establishing the relationships and practical elements of team-based problem solving. One class session presents practical tools for working in teams, ${ }^{28}$ and an in-class teambuilding exercise helps students identify how their group can best solve problems (see SI for materials). Engaging effectively in interdisciplinary inquiry-based learning requires a significant degree 
of intellectual humility, a characteristic we try to both model and teach. The process of being an astute observer requires students to put aside biases, listen actively, ask open-ended questions, and elicit and capture stories. ${ }^{29}$ This could also be called being a graceful learner, and we intentionally cultivate the skills of graceful learners through structured feedback and exercises.

\section{CONCLUSIONS}

The semester-long process of searching for greener solutions to hazardous chemicals, now entering its eighth year at UC Berkeley, applies the skills of graduate students in chemistry, environmental health sciences and engineering in interdisciplinary teams to solve complex sustainability challenges faced by partner organizations working in a variety of sectors, including electronics, personal care products, building materials, furnishings, polymers and textiles. A newer course at University of Victoria, B.C. has adapted the Greener Solutions model to teach similar skills to undergraduate students in civil engineering. In both courses, students develop a deep awareness of the importance of framing and solving problems through systems thinking. They investigate alternative strategies that draw from BID, beginning with an understanding of a chemical's function, an approach that allows the student teams to consider non-chemical solutions. While students from both Greener Solutions and

Green Safe Water have identified a few potentially ground-breaking innovations in particular projects, perhaps more importantly the courses continue to produce new ways of thinking about challenges in the fields of green chemistry and alternatives assessment.

\section{ASSOCIATED CONTENT}

Supporting Information

The following Supporting Information is available on the ACS Publications website at DOI:

$10.1021 /$ acs.jchemed...:

- Student accomplishments

- Examples of Greener Solutions student reports and presentations available online: https://bcgc.berkeley.edu/greener-solutions/

- Presentation slides from Greener Solutions team-building exercise

- Greener Solutions student comment form for in-class presentations

- Greener Solutions peer evaluation template 


\section{AUTHOR INFORMATION}

Corresponding Author

*E-mail: mschwarzman@berkeley.edu

\section{ACKNOWLEDGMENTS}

The authors wish to acknowledge Martin Mulvihill for his original vision and work in co-developing and co-teaching Greener Solutions, as well as for providing input on an early version of this article; current Greener Solutions co-instructors, Thomas McKeag and William Hart-Cooper; and the students and partner companies who have collaborated on framing problems and developing inspiring solutions. Thank you to Anne-Marie Daniel, Aditi Gupta, Charlotte Lafleur and others at UVic for their input developing Green Safe Water. Thanks also to Michael Wilson and the peer reviewers who provided input on this manuscript. Greener Solutions has received past funding from California EPA DTSC Grant \#14-T3945 (2015-2016) and US EPA Pollution Prevention grant \#99T19601 (2014-2016), and from select partner companies.

\section{REFERENCES}

1. Landrigan PJ, Fuller R, Acosta NJR, et al. The Lancet Commission on pollution and health. Lancet. 2018. doi:10.1016/S0140-6736(17)32345-0

2. McDonald BC, De Gouw JA, Gilman JB, et al. Volatile chemical products emerging as largest petrochemical source of urban organic emissions. Science (80- ). 2018; 359(6377). doi:10.1126/science.aaq0524

3. Safer Consumer Products. https://www.dtsc.ca.gov/SCP/ (accessed April 8, 2018).

4. Walmart Sustainability Hub. https://www.walmartsustainabilityhub.com/sustainablechemistry (accessed April 8, 2018).

475 5. Chemicals @ Target: Chemicals Policy \& Goals. https://corporate.target.com/_media/TargetCorp/csr/pdf/Target-Chemicals-Policy-andGoals.pdf (accessed April 8, 2018).

6. Trucost. Making the Business \&amp; Economic Case for Safer Chemistry.; 2015. http://asbcouncil.org/sites/default/files/asbcsaferchemicalsreportpresred.pdf. (accessed April $8,2018)$

7. Anastas PT, Warner JC. Green Chemistry: Theory and Practice. Oxford Univ Press New York. 1998. 
8. Anastas PT, Zimmerman JB. The United Nations sustainability goals: How can sustainable chemistry contribute? Curr Opin Green Sustain Chem. 2018; 13: 150-153. doi:10.1016/j.cogsc.2018.04.017

9. Anastas PT, Zimmerman JB, McDonough W, Braungart M. Peer Reviewed: Applying the Principles of Green Engineering to Cradle-to-Cradle Design. Environ Sci Technol. 2003. doi:10.1021/es032373g

10. Matlin SA, Mehta G, Hopf H, Krief A. One-world chemistry and systems thinking. Nat Chem. 2016. doi: $10.1038 /$ nchem. 2498

11. Constable DJC. The practice of chemistry still needs to change. Curr Opin Green Sustain Chem. 2017. doi:10.1016/j.cogsc.2017.08.002

12. United States Government Accountability Office. (2018). Chemical Innovation: Technologies to Make Processes and Products More Sustainable (p. 159). https://www.gao.gov/products/GAO$\underline{18-307}$ (accessed April 8, 2018).

13. Lavoie ET, Heine LG, Holder H, Rossi MS, Lee RE, Connor EA, Vrabel MA, DiFiore DM, Davies CL. Chemical Alternatives Assessment: Enabling Substitution to Safer Chemicals. Environ. Sci. Technol. 2010; 44(24) 9244-9249 https://pubs.acs.org/doi/abs/10.1021/es1015789

14. Anastas PT, McKeag TA. Shaping the Future of Additive Manufacturing: Twelve Themes from Bio-Inspired Design and Green Chemistry. Handb Green Chem. 2018; 10: 241-262. doi:10.1002/9783527628698.hgc122

16. Montana-Hoyos C, Fiorentino C. Bio-utilization, bio-inspiration, and bio-affiliation in design for sustainability: Biotechnology, biomimicry, and biophilic design. Int J Des Objects. 2016;10(3):118. doi:10.18848/2325-1379/CGP/v10i03/1-18

17. Faludi J, Hoang T, Gorman P, Mulvihill M. Aiding alternatives assessment with an uncertaintytolerant hazard scoring method. J Environ Manage. 2016; 182: 111-125. doi:10.1016/j.jenvman.2016.07.028

18. Data Commons. https://commons.healthymaterials.net (accessed April 8, 2018).

19. GreenScreen for Safer Chemicals. https://www.greenscreenchemicals.org/method (accessed April 8, 2018).

20. Jacobs MM, Malloy TF, Tickner JA, Edwards S. Alternatives assessment frameworks: Research 
needs for the informed substitution of hazardous chemicals. Environ Health Perspect. 2016;124(3):265-280. doi:10.1289/ehp.1409581

21. Buckley HL, Byrne AP, Hart-Cooper WM, Liao J. Next Generation Chemical Preservatives: Protecting People, Products, and Our Planet. Unpublished report. Berkeley Center for Green Chemistry, The University of California, Berkeley. 2014.

https://bcgctest.files.wordpress.com/2019/01/gs-preservatives-report_final.pdf (accessed July 23, 2019).

22. Augustine M, Cook E, Creel E, Raj S, and Wright J. Greener Solutions for Durable Water Repellency. Unpublished report. Berkeley Center for Green Chemistry, The University of California, Berkeley. 2017. https://bcgctest.files.wordpress.com/2018/03/gore-final-report-gs2017.pdf (accessed July 23, 2019).

23. Meadows DH. Places to Intervene in a System. 2005.

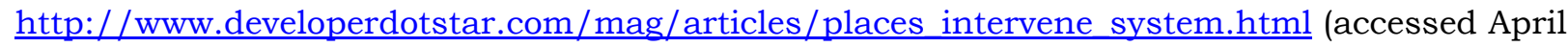
8, 2018).

24. Meadows DH. Thinking in Systems - a Primer.; 2008. doi:10.1080/09644016.2011.589585

25. Tickner JA, Schifano JN, Blake A, Rudisill C, Mulvihill MJ. Advancing safer alternatives through functional substitution. Environ Sci Technol. 2015;49(2):742-749. doi:10.1021/es503328m

26. Miyauchi Y, Ding B, Shiratori S. Fabrication of a silver-ragwort-leaf-like super-hydrophobic micro/nanoporous fibrous mat surface by electrospinning. Nanotechnology. 2006. doi:10.1088/0957-4484/17/20/019

27. Beckman S, Scott S, Wymore L. Collaborative Innovation: Exploring the Intersections among Theater, Art and Business in the Classroom. J Open Innov Technol Mark Complex. 2018;4(4):52. doi: $10.3390 /$ joitmc4040052

28. Borgatti S. Manual for Working in Teams. 1996-2004 Available at: http://www.analytictech.com/mb021/teamhint.htm (accessed August 19, 2019).

29. Payne K. Your Hidden Censor: What Your Mind Will Not Let You See. Sci Am. [online], June 11, 2013. https://www.scientificamerican.com/article/your-hidden-censor-what-your-mind-willnot-let-you-see/ (accessed April 8, 2018). 